\title{
Treatment of hallux valgus by modified McBride procedure: a 6-year follow-up
}

\author{
Istemi Yucel · Yuksel Tenekecioglu • \\ Tahir Ogut $\cdot$ Hayrettin Kesmezacar
}

Received: 21 November 2009/ Accepted: 26 April 2010/Published online: 27 May 2010

(C) The Author(s) 2010. This article is published with open access at Springerlink.com

\begin{abstract}
Background Surgical decision-making was reevaluated by comparison with an algorithm designed to analyze treatment of hallux valgus deformities.

Materials and methods A modified McBride procedure was performed on 52 feet of 35 patients with hallux valgus deformity. From this series, 36 feet of 21 patients were evaluated preoperatively, early postoperatively, and late postoperatively by means of subjective evaluation and clinical and radiological findings.

Results The hallux valgus angle preoperatively, early postoperatively, and late postoperatively was $32.7 \pm 8.5^{\circ}$, $10.1 \pm 6.9^{\circ}$, and $20.6 \pm 9.5^{\circ}$, respectively. Hallux valgus recurrence of $72.2 \%$ was observed. Subjective results were better and the patients rated their satisfaction with the procedure as excellent or high in 23 cases $(63.9 \%)$ and moderate, low, or unsatisfactory in 13 cases $(36.1 \%)$. Conclusions This level of patient satisfaction demonstrates that the McBride procedure is an efficient approach for eliminating pain due to hallux valgus deformity.
\end{abstract}

I. Yucel $(\bowtie)$

Department of Orthopaedics and Traumatology,

Faculty of Medicine,

University of Duzce, Duzce, Turkey

e-mail: istemiyucel@yahoo.com

Y. Tenekecioglu $\cdot$ T. Ogut $\cdot$ H. Kesmezacar

Department of Orthopaedics and Traumatology,

Cerrahpasa Faculty of Medicine, University of Istanbul,

Istanbul, Turkey
Keywords Hallux valgus $\cdot$ McBride . Distal soft tissue procedure $\cdot$ Bunion

\section{Introduction}

The term "hallux valgus" was first introduced in 1871 by Carl Heuter [1, 2], who defined it as "lateral deviation of the great toe from the medial plane of the body" that, together with medial deviation of the first metatarsal, accompanies static subluxation of the first metatarsophalangeal (1.MTP) joint.

In surgical treatment of hallux valgus, more than 150 different surgical procedures, many of them modifications of others, have been described. Surgical approaches include metatarsal and phalangeal osteotomies, arthrodesis, resection arthroplasties, and amputations. Silver [3] emphasized the importance of muscle imbalance, and in 1923, defined the "distal soft tissue procedure" (DSTP) as excision of the medial prominence, release of the adductor tendon and the lateral capsule, and plication of the medial capsule. In 1928, McBride [4] modified Silver's method and proposed excision of the lateral sesamoid, release of the adductor tendon, and resuturing of the tendon to the head of the first metatarsal order to correct the metatarsal varus deformity. McBride revised and refined his approaches in 1935 [5] and 1954 [6]. Since then, many further modifications of the McBride procedure have been used in the treatment of hallux valgus deformity. The purpose of this study is to evaluate the late-term results of hallux valgus treatment with a modified DSTP as performed following the method of McBride. We undertook a retrospective cohort study of patients who had undergone the McBride procedure for the repair of hallux abductovalgus, with the primary aim of determining the association of 
radiographic angular changes with patient satisfaction following the operation.

\section{Materials and methods}

Fifty-two feet of 35 patients with hallux valgus deformity were treated by the McBride procedure in our orthopedics and traumatology department. The inclusion criteria included: moderate to severe hallux valgus with metatarsus primus varus, passively correctable hallux valgus, supple first metatarsocuneiform joint with passively correctable first intermetatarsal gap, age 18 years or older, and symptomatology that was unresponsive to conservative interventions. Specific patient exclusion criteria were as follows: a diagnosis of diabetes mellitus or rheumatoid arthritis, hallux rigidus (defined as less than $10^{\circ}$ first metatarsophalangeal joint dorsiflexion), postoperative followup period of less than 12 months, or lack of preoperative and final follow-up radiographs in medical record.

\section{Surgical procedure}

Under tourniquet control, placed around the thigh, the first incision is made on the dorsal aspect of the first intermetatarsal space. The adductor hallucis tendon is released, a lateral joint longitudinal capsulotomy is performed, and a second midline incision is made. The medial eminence is excised in line with the medial aspect of the first metatarsal shaft. This is followed by medial capsulorrhaphy and suturing of the released adductor hallucis tendon to the capsule. Postoperatively, a compressive bandage is applied and the patient is allowed to walk on a postoperative shoe with partial weight-bearing.

\section{Patient evaluation}

An "evaluation form for the results of treatment with the McBride procedure in hallux valgus patients" was given to all patients in order to evaluate clinical, radiological, and subjective aspects of treatment. In the first part of the form, demographic and registration information, systemic diseases, history of hallux valgus in first-degree relatives, presence of another foot deformity, type of preoperative shoe, date of operation, follow-up time, and preoperative pain were documented. In the second part, preoperative, early postoperative at 1 month, and late postoperative radiological measurements at the last follow-up with weight-bearing [hallux valgus angle (HVA), first intermetatarsal angle (1-2.IMA), first distal metatarsal articular angle (1.DMAA), and tibial sesamoid position according to the relation of the tibial sesamoid with the longitudinal axis of the first metatarsal], presence of 1.MTP joint arthrosis, use of orthotic devices, and postoperative care methods were documented. Results of the physical examination of the patient were recorded in the last part of the form and included the following: level of self-reported pain in the 1.MTP joint, metatarsalgia, bunion deformity, pronation deformity of great toe, overriding of the first and second toes, range of motion (ROM) of the 1.MTP joint, and motor and neurological examination of the foot. Finally, patients were asked to rate, between 0 and 5 , their level of satisfaction with the operation ( 0 , no satisfaction; 1 , very low; 2, low; 3, moderate; 4, high; 5, excellent).

Statistical analysis was performed using SPSS 11.0 for Windows. The one-sample $t$-test and paired-samples $t$-test were used for comparisons of mean preoperative, early postoperative, and late postoperative values of HVA, 1-2.IMA, and DMAA. Spearman's correlation test was used for comparison of mean preoperative and late postoperative values of HVA according to patients' satisfaction values. Independent-samples $t$-test was used for comparison of mean preoperative and postoperative values of HVA and 1-2.IMA between algorithm-matched and unmatched cases, of mean preoperative and postoperative values of HVA between preoperative values of 1-2.IMA higher or lower than $15^{\circ}$, and of mean preoperative and postoperative values of HVA between preoperative values of DMAA higher or lower than $10^{\circ} . p<0.05$ was considered to indicate statistical significance.

The study was reviewed by appropriate ethics committee and has therefore been performed in accordance with the ethical standards laid down in an appropriate version of the 1964 Declaration of Helsinki. All persons gave their informed consent prior to inclusion in the study.

\section{Results}

Thirty-one of the patients $(88.6 \%)$ were female, and four (11.4\%) were male. Of this series, final evaluation was conducted on 36 feet of 21 female patients: 15 patients (71.4\%) underwent bilateral (all in two stages), and 6 (28.6\%) had unilateral surgery; 14 patients were lost to follow-up. Nineteen left feet $(52.8 \%)$ and 17 right feet $(47.2 \%)$ were treated. Mean follow-up time was $79.6 \pm 52.6$ months (range 12-181 months). Mean patient age at late postoperative follow-up was $46.8 \pm 15.9$ years (range 18-80 years).

Patients were evaluated according to the evaluation form for the results of treatment with the McBride procedure in hallux valgus patients.

Nineteen patients $(90.5 \%)$ had a history of hallux valgus, and one patient $(4.8 \%)$ reported rheumatoid arthritis in a first-degree relative. In 17 feet (47.2\%), additional orthopedic deformities were detected preoperatively: 
13 pes planus, 3 hammer toes, and 1 bunionette. Of the 21 patients, $12(57.1 \%)$ wore poorly fitting, narrow shoes with high heels, while 9 (42.9\%) wore properly fitting, wide shoes. Preoperative pain was reported in 35 (97.2\%) of the 36 treated feet.

Preoperative pain was the main surgical indication in 35 feet $(97.2 \%)$. However, in one case $(2.8 \%)$ the patient with mild pain underwent surgery due to complaints about the appearance of her foot and her inability to wear correctly fitting shoes. Patients were divided into three groups depending on the HVA measurement on radiographs: mild $\left(\mathrm{HVA}<20^{\circ}\right)$, moderate $\left(\mathrm{HVA}=21-40^{\circ}\right)$, or severe $\left(\right.$ HVA $\left.>40^{\circ}\right)$. Early and late postoperative changes in HVA and 1-2.IMA compared with preoperative values are presented in Table 1.

Mean HVA, 1-2.IMA, and 1.DMAA were measured at the preoperative, and early and late postoperative stages. The mean preoperative HVA was $32.7 \pm 8.5^{\circ}$. The mean $1-2 . I M A$ was $13.8 \pm 3.9^{\circ}, 6.9 \pm 3.2^{\circ}$, and $7.9 \pm 2.7^{\circ}$ measured preoperatively, and early and late postoperatively, respectively. Early and late postoperative mean degree of correction of HVA compared with preoperative 1-2.IMA was measured, and the results are presented in Table 2.

At early postoperative assessment, correction of $22.6^{\circ}$ of HVA was obtained. A statistically significant difference was found between preoperative and early postoperative mean HVA values $(p=0.000)$. At mean follow-up of $79.6 \pm 52.6$ months, correction of $12.1^{\circ}$ was preserved between preoperative and late-postoperative HVA; this result was also statistically significant $(p=0.000)$. However, statistically significant loss of correction of $10.5^{\circ}$ occurred between early $\left(10.1 \pm 6.9^{\circ}\right)$ and late $(20.6 \pm$ $\left.9.5^{\circ}\right)$ postoperative HVA $(p=0.000)$.

The mean angle of correction for 1-2.IMA at the early postoperative stage was $6.9^{\circ}$, and the difference between the preoperative and early postoperative 1-2.IMA values was statistically significant $(p=0.000)$. At mean follow-up of $79.6 \pm 52.6$ months, statistically significant $(p=0.000)$ correction of the 1-2.IMA of $5.9^{\circ}$ was preserved between preoperative and postoperative stages. A $1.0^{\circ}$ loss of correction of the 1-2.IMA occurred between the early $\left(6.9 \pm 3.2^{\circ}\right)$ and late $\left(7.9 \pm 2.7^{\circ}\right)$ postoperative stages, but this difference was not statistically significant $(p=0.122)$.

The changes between preoperative and late postoperative HVA values were compared in cases in which the 1-2.IMA was greater or less than $15^{\circ}$. Statistically significant differences were found between preoperative and late postoperative mean HVA values in cases in which 1-2.IMA was greater or less than $15^{\circ}(p=0.019$, $p=0.046$; respectively).

The value of 1.DMAA was $15.2 \pm 6.7^{\circ}, 9.6 \pm 4.6^{\circ}$, and $12.3 \pm 8.2^{\circ}$ at the preoperative, and early and late postoperative stages, respectively. The mean amount of correction in the 1.DMAA at the early postoperative stage was $5.6^{\circ}$. The difference between preoperative and early postoperative mean 1.DMAA values $(p=0.000)$ was statistically significant. With mean follow-up of $79.6 \pm$ 52.6 months, correction of $2.9^{\circ}$ was preserved between preoperative and postoperative 1.DMAA, which was not statistically significant $(p=0.088)$. Between early and late postoperative 1.DMAA, $2.7^{\circ}$ loss of correction was found, which was not statistically significant $(p<0.066)$.

The changes between preoperative and late postoperative HVA in feet in which 1.DMAA was greater or less than $10^{\circ}$ were compared. In 12 feet $(33.3 \%)$, preoperative

Table 2 Early and late postoperative mean correction of HVA according to preoperative 1-2.IMA

\begin{tabular}{lll}
\hline HVA & \multicolumn{2}{l}{ Preoperative 1-2.IMA } \\
\cline { 2 - 3 } & $\leq 15^{\circ}$ & $>15^{\circ}$ \\
\hline Preoperative & $30.7 \pm 7.5^{\circ}$ & $38.8 \pm 9.0^{\circ}$ \\
$\begin{array}{l}\text { Early postoperative } \\
\quad(\text { correction) }\end{array}$ & $9.4 \pm 7.3^{\circ}\left(21.3^{\circ}\right)$ & $12.2 \pm 5.0^{\circ}\left(26.6^{\circ}\right)$ \\
$\begin{array}{l}\text { Late postoperative } \\
(\text { correction) }\end{array}$ & $18.7 \pm 6.6^{\circ}\left(12.0^{\circ}\right)$ & $26.3 \pm 14.4^{\circ}\left(14.0^{\circ}\right)$ \\
\hline
\end{tabular}

Table 1 Results of McBride procedure according to degree of deformity

\begin{tabular}{lllc}
\hline $\begin{array}{l}\text { Change of HVA and } \\
\begin{array}{l}\text { 1-2.IMA according } \\
\text { to preoperative HVA }\end{array}\end{array}$ & $\begin{array}{l}\text { Mild } \\
\left(\mathrm{HVA}<20^{\circ}\right),\end{array}$ & $\begin{array}{l}\text { Moderate } \\
\left(\mathrm{HVA}=21-40^{\circ}\right), \\
n / \mathrm{HVA}\left({ }^{\circ}\right)\end{array}$ & $\begin{array}{l}\text { Severe } \\
\left(\mathrm{HVA}>40^{\circ}\right), \\
n / \mathrm{HVA}\left({ }^{\circ}\right)\end{array}$ \\
\hline $\begin{array}{l}\text { Mean HVA } \\
\text { Preoperative }\end{array}$ & $1 / 17^{\circ}$ & $28 / 29.8 \pm 4.8^{\circ}$ & $7 / 46.7 \pm 3.7^{\circ}$ \\
Early postoperative & $34 / 9.2 \pm 5.8^{\circ}$ & $2 / 25.5 \pm 4.9^{\circ}$ & - \\
Late postoperative & $22 / 14.8 \pm 3.6^{\circ}$ & $12 / 26.7 \pm 3.2^{\circ}$ & $2 / 48.5 \pm 6.4^{\circ}$ \\
Mean 1-2.IMA & & & \\
Preoperative & $1 / 7^{\circ}$ & $28 / 13.0 \pm 3.2^{\circ}$ & $8 / 17.7 \pm 3.8^{\circ}$ \\
Early postoperative & $1 / 7^{\circ}$ & $28 / 6.9 \pm 2.8^{\circ}$ & $8 / 6.7 \pm 4.9^{\circ}$ \\
Late postoperative & $1 / 7^{\circ}$ & $28 / 8.0 \pm 3.0^{\circ}$ & $8 / 7.6 \pm 1.7^{\circ}$ \\
\hline
\end{tabular}


1.DMAA was less than $10^{\circ}$, whereas in $24(66.7 \%)$ it was greater than $10^{\circ}$. A statistically significant difference was found between preoperative and late postoperative mean HVA values in cases in which DMAA was greater than $10^{\circ}$ $(p=0.042)$, whereas the difference was not statistically significant between preoperative and late postoperative mean HVA values in cases in which DMAA was less than $10^{\circ}(p=0.593)$. In Table 3 , early and late postoperative mean degrees of HVA correction, as determined by 1.DMAA values greater or less than $10^{\circ}$, are presented.

Preoperative and late postoperative sesamoid positions are presented in Table 4. Preoperatively, 4 feet $(11.1 \%)$ had congruous 1.MTP joints, while 32 (88.9\%) had incongruous joints. At the early postoperative stage, 35 joints $(97.2 \%)$ were congruous, and $1(2.8 \%)$ was incongruous; at the late postoperative stage, 20 (55.6\%) were congruous and 16 (46.2\%) were incongruous. Preoperatively, 1.MTP joint arthrosis was detected in 16 feet (44.4\%). At late postoperative follow-up, 23 feet $(63.9 \%)$ had arthrosis. In addition to shoe modification, orthotics were used as a conservative modality preoperatively and postoperatively in $61.1 \%$ and $80.6 \%$ of feet, respectively. Only one patient $(2.8 \%)$ was treated postoperatively with a cast, whereas the feet of the other patients (97.2\%) were treated with compressive bandages. At late postoperative follow-up, physical examination of patients revealed bunion deformity in 17 feet $(47.2 \%)$, pain in the 1.MTP joint in 13 feet $(36.1 \%)$, overriding of the first and second toes in

Table 3 Early and late postoperative mean correction of HVA according to preoperative 1.DMAA

\begin{tabular}{lll}
\hline HVA & \multicolumn{2}{l}{ Preoperative 1.DMAA } \\
\cline { 2 - 3 } & $<10^{\circ}$ & $>10^{\circ}$ \\
\hline Preoperative & $28.7 \pm 7.7^{\circ}$ & $34.8 \pm 9.3^{\circ}$ \\
$\begin{array}{c}\text { Early postoperative } \\
\quad(\text { correction) }\end{array}$ & $8.6 \pm 5.4^{\circ}\left(20.1^{\circ}\right)$ & $10.1 \pm 7.5^{\circ}\left(24.7^{\circ}\right)$ \\
$\begin{array}{c}\text { Late postoperative } \\
\quad \text { correction) }\end{array}$ & $19.4 \pm 5.4^{\circ}\left(9.3^{\circ}\right)$ & $21.3 \pm 11.1^{\circ}\left(13.5^{\circ}\right)$ \\
\hline
\end{tabular}

Table 4 Tibial sesamoid positions before and after McBride procedure

\begin{tabular}{|c|c|c|c|c|}
\hline \multicolumn{2}{|c|}{ Preoperative position } & \multicolumn{3}{|c|}{ Late postoperative position } \\
\hline $\begin{array}{l}\text { Tibial sesamoid } \\
\text { subluxation }(\%)\end{array}$ & $n$ & Medial & Central & Latera \\
\hline 100 & 20 & 6 & 10 & 4 \\
\hline 75 & 2 & 1 & 1 & 0 \\
\hline 50 & 7 & 4 & 3 & 0 \\
\hline 25 & 7 & 3 & 4 & 0 \\
\hline$N$ & 36 & 14 & 18 & 4 \\
\hline
\end{tabular}

Table 5 Personal evaluation and satisfaction of patients with the operation at last follow-up

\begin{tabular}{lcc}
\hline & $n$ & Ratio (\%) \\
\hline 0-No satisfaction & 1 & 2.8 \\
1-Very low satisfaction & 3 & 8.3 \\
2-Low satisfaction & 6 & 16.7 \\
3-Moderate satisfaction & 2 & 5.6 \\
4-High satisfaction & 12 & 33.3 \\
5-Excellent satisfaction & 12 & 33.3 \\
\hline
\end{tabular}

13 feet $(36.1 \%)$, metatarsalgia in 9 feet $(25.0 \%)$, and pronation in the great toe in 4 feet $(11.1 \%)$. Joint flexion and extension of 1.MTP was $31.3 \pm 8.8^{\circ}$ and $42.2 \pm 12.1^{\circ}$, respectively. Neurological examination of the feet revealed hypoesthesia over either the great toe or the medial incision in eight feet $(22.2 \%)$; three of them $(8.3 \%)$ were present preoperatively.

Patient satisfaction with the operation is reported in Table 5. The mean patient satisfaction rating was $3.6 \pm 1.5$. In Fig. 1, radiographs and digital images of the right foot of a 50-year-old-female patient reporting moderate satisfaction at 120 months of follow-up are shown. In 26 feet $(72.2 \%)$ with late postoperative HVA greater than $15^{\circ}$, the mean satisfaction rating of the patients was $3.2 \pm 1.6$, and in 10 feet $(27.8 \%)$ with HVA less than $15^{\circ}$ the patient rating was $4.5 \pm 0.5$.

Four early postoperative complications were detected. In two feet $(5.6 \%)$, early postoperative superficial infections were observed. One foot healed with antibiotics alone (Fig. 2, left foot), but the other one required surgical debridement. In one patient (2.8\%), deep vein thrombosis occurred. Early postoperative hallux varus was detected in one foot (preoperatively $25^{\circ}$ valgus, early postoperative stage $4^{\circ}$ varus, and late postoperative stage $18^{\circ}$ valgus) and treated with early modification of the compressive bandage.

\section{Discussion}

Many operations to remedy hallux valgus are problematic as they do not provide a comprehensive solution for the deformity. Ideally, hallux valgus surgery comprises correction of the HVA and the 1-2.IMA, establishment of a congruous 1.MTP joint with correction of sesamoid alignment, bunion excision, establishment of a functional ROM of the 1.MTP, and maintenance of the normal weight-bearing mechanism of the foot [1]. Surgical interventions causing metatarsal shortening or dorsal deviation of the head of the first metatarsal, or with a high risk of avascular necrosis, probable failure at short-term follow- 
Fig. 1 a Preoperative radiograph of the right foot of a 50-year-old female patient (HVA $25^{\circ}, 1-2 . I M A ~ 11^{\circ}$, 1.DMAA $6^{\circ}$ ). b Late postoperative radiograph of the right foot of a 50-year-old female patient reporting moderate satisfaction after 120 months of follow-up (HVA $17^{\circ}, 1-2$. IMA $9^{\circ}, 1$. DMAA $\left.10^{\circ}\right)$. c Digital image of the right foot of a 50-year-old female patient reporting moderate satisfaction after 120-month follow-up
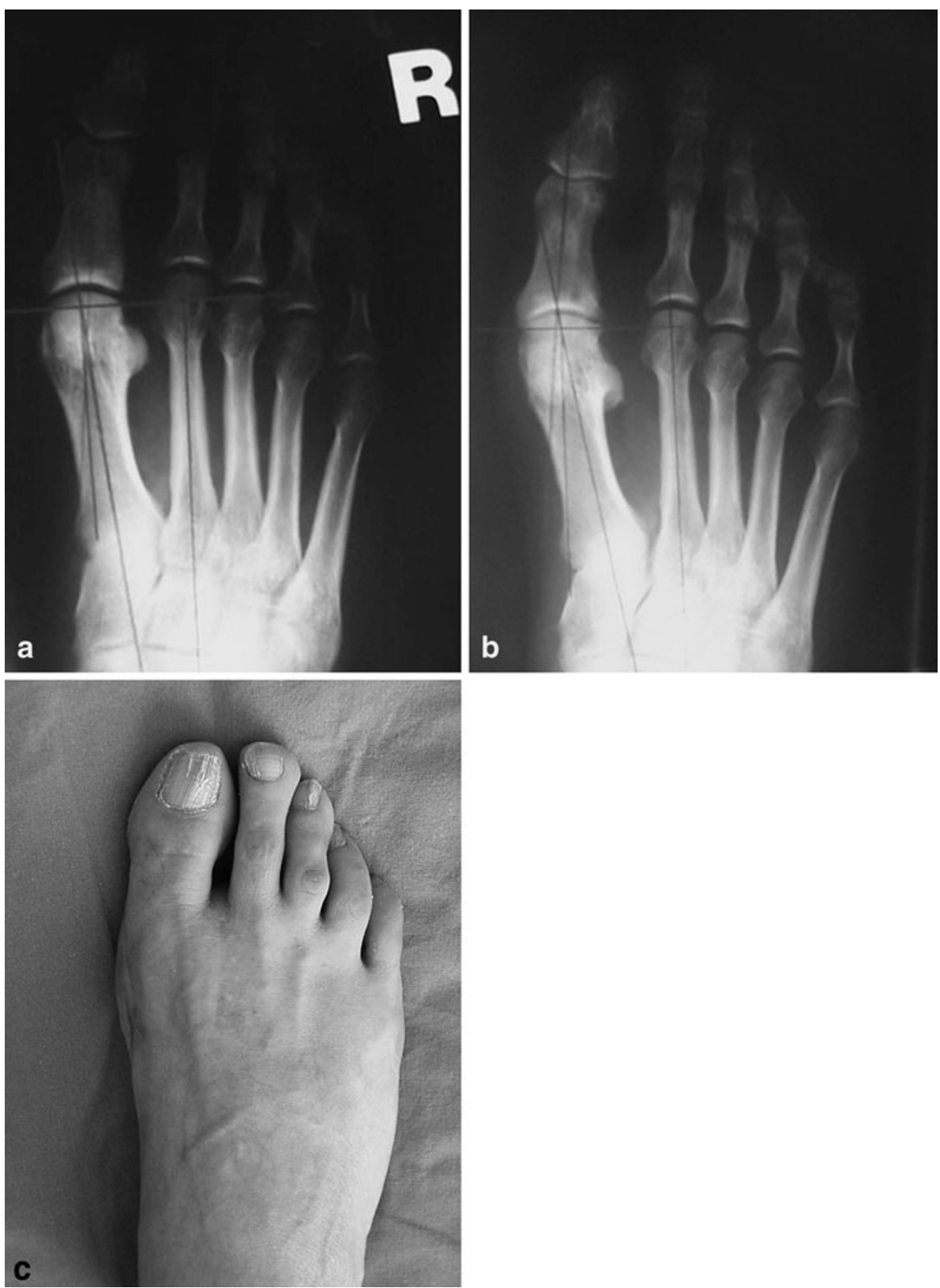

up, or the need to use foreign bodies, with the probability of local reactions, should be avoided.

The transverse and oblique heads of the adductor hallucis inserting on the proximal phalanx and the flexor hallucis brevis are the main deforming forces in hallux valgus deformities [4]. McBride [4] believed that, with increasing deformity, the sesamoid within the adductors is pulled laterally and creates a force pulling the head of the first metatarsal medially. Thus, the abnormal mechanical force should be removed and normal alignment of the phalanges and metatarsals achieved by incising the conjoint tendon and transferring it to the head of the first metatarsal; the lateral sesamoid may be excised if it shows degenerative changes and dysplasia [6]. Bursae and bunions should be excised. In this way, ideal but nonetheless "conservative" treatment could be attained. McBride [5] observed that, if adductor tightness was removed from the proximal phalanx, the valgus position of the great toe improved. He believed that correction of rotation and valgus is possible only when the forces acting medially and laterally are balanced. Since metatarsal osteotomies add a fracture to this complex situation, they are not the most effective method of correction. McBride [5] reported that, with his method, deformity was corrected without the need for metatarsal osteotomy or resection; normal alignment of the toes could be restored and the mechanical forces 
Fig. 2 a Preoperative radiograph of the feet of a 27-year-old female patient (right $\mathrm{HVA} 50^{\circ}$, 1-2.IMA $13^{\circ}$, 1.DMAA $26^{\circ}$; left $\mathrm{HVA} 50^{\circ}$, 1-2.IMA $14^{\circ}, 1$.DMAA $24^{\circ}$ ). b Late postoperative radiograph of both feet of a 27-year-old female patient with moderate $(R)$ and no $(L)$ satisfaction after 111 months of follow-up (right HVA $10^{\circ}, 1-2$. IMA $5^{\circ}$, 1.DMAA $9^{\circ}$; left $\mathrm{HVA} 20^{\circ}$, 1-2.IMA $6^{\circ}, 1$. DMAA $11^{\circ}$ ). c Digital image of feet of a 27-year-old female patient with moderate $(R)$ and no $(L)$ satisfaction after 111 months of follow-up
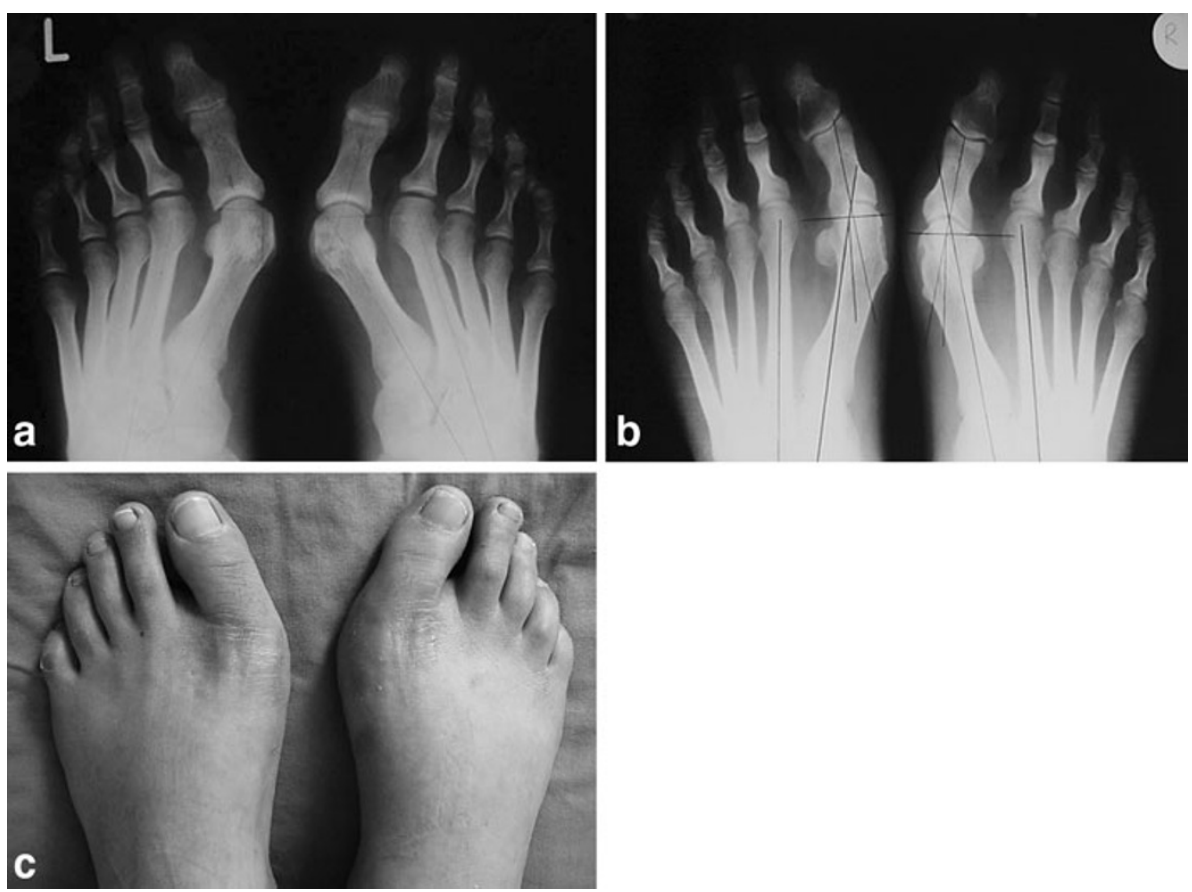

causing deformity removed. Moreover, because the incision is remote from the site of irritation, the operation has a short recovery period and functional results are very good, eventually allowing the patient to wear normal shoes.

Many modifications of the McBride procedure have been proposed. DuVries added a medial incision to the method and sutured the adductor tendon to the heads of the first and second metatarsals after suturing the two metatarsals together. $\mathrm{He}$ also excised the fibular sesamoid in cases of more than $50 \%$ subluxation [7, 8]. Another modification of the procedure consists of transferring the released adductor hallucis tendon to the medial side of the head of the first metatarsal by passing it under the plantar side of the metatarsal head [9]. Sammarco and Conti stated that DSTP, and if necessary metatarsal osteotomy, could be done via a single incision [10]. Mann, Coughlin, and Pfeffinger evaluated some of the more problematic aspects of the McBride procedure, and as a result decided not to excise the lateral sesamoid but to add a proximal crescentic metatarsal osteotomy $[1,10,11]$. The incised adductor tendon is sutured to the medial capsule by passing it medially through the metatarsal neck or to the lateral side of the metatarsal head [12].

Two angles primarily describe anatomic deformity and the results of surgical treatment: HVA and 1-2.IMA. However, there are no widely accepted standard postoperative radiographic measurements, especially when metatarsal osteotomy has been performed. Of the five different measurement techniques for HVA [13], we used the method described by Mitchell, in which the metatarsal line passes from the center of the joint surface of the metatarsal head. All preoperative and early postoperative measurements for HVA are done again according to Mitchell's method as well as late postoperative measurements. This measurement is not affected by excision of bunions or metatarsal osteotomies and 1.MP arthrodesis.

A previous study suggested that, if 1-2.IMA is greater than $15^{\circ}$ or correction of HVA of more than $20^{\circ}$ is needed, DSTP should be accompanied by proximal metatarsal osteotomy [1]. Meyer et al. [9] recommended metatarsal osteotomy instead of the McBride procedure when HVA $>50^{\circ}$ and 1-2.IMA $>14^{\circ}$. In our series, preoperative 1-2.IMA was found to be greater than $15^{\circ}$ in 15 feet $(41.7 \%)$ and correction of the preoperative HVA by more than $20^{\circ}$ was required in 13 feet $(36.1 \%)$. It is obvious that, if metatarsal osteotomies had been added to the DSTPs, the recurrence rate would have been much lower.

The main pathology in congruous hallux valgus is the increase in the 1.DMAA [14]. In a study of 878 cases [15], 21 feet with increased 1.DMAA were operated on by double or triple metatarsal and phalangeal osteotomies. A strong correlation between preoperative and postoperative HVA was observed, and periarticular osteotomies were suggested in the presence of increased 1.DMAA. In this study, $33.3 \%$ of 1. DMAA values were higher than $10^{\circ}$ and metatarsal and phalangeal osteotomies could be added.

Numerous investigations on the efficacy of the McBride procedure have been reported. In one study, the authors achieved a decrease of HVA to less than $16^{\circ}$ in $59 \%$ of feet treated by a modified McBride procedure, and in $76 \%$ when proximal crescentic osteotomy was added [1]. They strongly advocated the combination of these two 
procedures when HVA correction of more than $20^{\circ}$ is necessary and when the 1-2.IMA is greater than $15^{\circ}$. Our results are not better; we achieved HVA values less than $16^{\circ}$ only in $36.1 \%$ of cases at mean follow-up of $79.6 \pm 52.6$ months, but in that study mean follow-up of 5 years was shorter than in this study. Kitaoka and Patzer [16] reported $4.8^{\circ}$ and $1.7^{\circ}$ increases in HVA and 1-2.IMA, respectively, with bunionectomy and medial capsular plication in 49 feet, with a follow-up period of 4.8 years and applied revision in 16 feet. In that study, HVA was lowered from $33.3^{\circ}$ to $14.2^{\circ}$ and 1-2.IMA from $12.6^{\circ}$ to $5.7^{\circ}$. In 21 female athletes operated on due to pain during running, HVAs of $25-50^{\circ}$ were lowered to between $10^{\circ}$ and $15^{\circ}$ in 16 patients and to $>15^{\circ}$ in 5 patients; $1-2$.IMAs of $10-18^{\circ}$ were lowered to $<10^{\circ}$ in 17 patients and to $>10^{\circ}$ in 4 patients [9]. In a study of 39 cases, a mean late postoperative 1-2.IMA of $5.6^{\circ}$ was reported, which led to the conclusion that the primary etiological factor in hallux valgus is not metatarsocuneiform joint instability [17]. Using pedobarographic measurements, Geary and Mittal [18] found a significant decrease in pressure, an increase in contact surface of the great toe and the medial side of the foot, and a decrease in forefoot width. In a study using the DuVries modification [8, 19], HVA was lowered from $24.8^{\circ}$ to $17.1^{\circ}$, and $1-2$. IMA from $11.3^{\circ}$ to $10.5^{\circ}$.

Gebuhr et al. [20] found more correction when lateral sesamoidectomy and lateral capsulotomy were performed and strongly asserted that the McBride procedure could be used in every patient without 1.MTP joint arthrosis. Archibald and Hamilton [21] concluded that, with some modifications, good long-term results could be obtained with the McBride procedure in patients without arthrosis of the 1.MTP joint.

Several methods to define the position of the sesamoid have been described [22-25], including the one proposed by Mann used in this study [23]. The position of the tibial sesamoid on the anteroposterior radiograph was described as medial, lateral, or central in relation to a line drawn along the center of the longitudinal axis of the first metatarsal. The first metatarsal head is bisected, and the sesamoid is divided into quarters. The position of the tibial sesamoid was considered to be medial if $75 \%$ of its width was medial to the central line, and lateral if $75 \%$ was lateral to the central line; otherwise, the sesamoid was considered to be centrally located. According to Mann, sesamoid position does not affect the severity and frequency of postoperative pain. In our study, the late postoperative medial or central sesamoid position of $88.9 \%$ demonstrates that the aim of correcting metatarsus primus varus was achieved.

An algorithm prepared by Coughlin and Mann [1] used a systematic approach in their analysis of hallux valgus deformities and showed that the McBride procedure could be applied in a congruous joint without an angular limitation, and in an incongruous joint in the following four situations: (1) $\mathrm{HVA}<30^{\circ}$ and $1-2 . \mathrm{IMA}<13^{\circ}$ (proximal crescentic osteotomy may be added), (2) HVA $<40^{\circ}$ and 1-2.IMA $>13^{\circ}$ (with proximal metatarsal osteotomy), (3) HVA $>40^{\circ}$ and 1-2.IMA $>20^{\circ}$ (with proximal metatarsal osteotomy), and (4) hypermobile 1.MTC (metatarsocuneiform) joint (with 1.MTC joint fusion). We retrospectively evaluated our patients using this algorithm and found that in 17 of 36 feet $(47.2 \%)$ our approach was consistent with that recommended by the algorithm. These 17 cases comprised all 4 feet having congruous 1.MTP joints and 13 of 32 feet $(40.6 \%)$ with an incongruous 1.MTP joint. In addition, in these 17 feet, the preoperative HVA changed from $25.9 \pm 2.9^{\circ}$ to $17.8 \pm 5.4^{\circ}$ late postoperatively, while the $1-2$.IMA changed from $11.7 \pm 3.2^{\circ}$ to $7.9 \pm 2.8^{\circ}$. Preoperative HVA and 1-2.IMA of the remaining unmatched 19 cases changed from $38.8 \pm 7.1^{\circ}$ to $23.2 \pm 11.7^{\circ}$ and from $15.6 \pm 3.6^{\circ}$ to $8.0 \pm 2.7^{\circ}$, respectively. Between algorithm-matched and algorithm-unmatched cases, statistically significant differences were detected between preoperative and late postoperative HVA ( $p=0.000$ and $p=0.000)$ and between preoperative and late postoperative 1-2.IMA values $(p=0.000$ and $p=0.001)$.

Considering the important role of the 1.MTP joint in the toe-off phase of gait, its ROM should be sufficient. In longstanding hallux valgus deformities, degenerative changes appear and joint motion becomes restricted [26]. In this study, the occurrence of arthrosis in the 1.MTP joint increased from an initial 16 feet $(44.4 \%)$ to 20 feet (55.6\%) at last follow-up. This is probably related to the increase in HVA. Late postoperative ROM of the first metatarsal was assessed as restricted, with $42.2^{\circ}$ of 1.MTP joint extension (range $10-60^{\circ}$ ) and $31.3^{\circ}$ of flexion (range $10-40^{\circ}$ ). If we take into consideration that most of our patients live sedentary lives and have very low levels of athletic activity, this ROM may be viewed as sufficient, and a sedentary lifestyle may be accepted as an inclusion criteria in selected cases. In previous studies [1, 7-9, 27, 28], 1.MTP joint ROM between $61^{\circ}$ and $84^{\circ}$ and extension between $8^{\circ}$ and $23^{\circ}$ were reported.

At late follow-up (FU), $47.2 \%$ of patients have a bunion deformity, and $36.1 \%$ have overriding of the first and second toes. These results parallel the $72.2 \%$ recurrence of hallux valgus deformity.

Mean patient satisfaction according to the six-point scale $(0-5)$ was $3.6 \pm 1.5$. The relationship between patients' self-reported satisfaction and HVA is shown in Table 6. No correlation was found between preoperative HVA values and patient satisfaction $\left(r_{\mathrm{s}}=-0.230, p=0.177\right)$. A weak negative correlation was found between late postoperative HVA and patient satisfaction $\left(r_{\mathrm{s}}=-0.471, p=0.004\right)$. It is clear that patient satisfaction decreases as HVA values increase. 
Table 6 Relation of mean late postoperative HVA values with patients' personal evaluation of satisfaction

\begin{tabular}{|c|c|c|c|c|c|c|}
\hline \multirow[t]{2}{*}{ HVA } & \multicolumn{6}{|c|}{ Patient evaluation } \\
\hline & 0 & 1 & 2 & 3 & 4 & 5 \\
\hline Preoperative & $50.0^{\circ}$ & $32.7 \pm 4.0^{\circ}$ & $34.2 \pm 9.8^{\circ}$ & $28.0 \pm 4.2^{\circ}$ & $34.4 \pm 8.4^{\circ}$ & $29.7 \pm 8.2^{\circ}$ \\
\hline Early postoperative & $8.0^{\circ}$ & $16.3 \pm 6.7^{\circ}$ & $10.5 \pm 3.8^{\circ}$ & $6.0 \pm 2.8^{\circ}$ & $9.0 \pm 8.1^{\circ}$ & $10.4 \pm 7.3^{\circ}$ \\
\hline Late postoperative & $20.0^{\circ}$ & $29.7 \pm 13.6^{\circ}$ & $24.8 \pm 6.4^{\circ}$ & $18.5 \pm 2.1^{\circ}$ & $21.3 \pm 12.1^{\circ}$ & $16.0 \pm 5.5^{\circ}$ \\
\hline
\end{tabular}

Previous studies [7, 8, 17, 20, 28, 29] reported patient satisfaction between $70.6 \%$ and $93 \%$. In one study [1], mean satisfaction was found to be $92 \%$. The criteria for satisfaction were alleviation of pain (achieved in $74 \%$ of cases), decrease in deformity (18\%), and decrease in bunion size (8\%). Causes of dissatisfaction were pain in the 1.MTP joint and the shape of the great toe, equally. The authors concluded that, in mild and intermediate cases of hallux valgus deformity, the McBride procedure yields satisfactory results, but in severe cases, it may not be sufficient [1].

Hallux varus complication following surgery is most frequently observed after use of the McBride procedure. Although in previous studies hallux varus complication ratios of 2/39 [5], 6/72 [8], 3/39 [17], and 13/109 [23] were reported, we saw only one in 36 cases. Two different types of postoperative hallux varus complications have been defined [30]: The static type, which most frequently occurs after methods such as those of Keller-Brandes, Mayo, and Hohmann, is due to overexcision of bunions or joint laxity. The dynamic type is observed after DSTP and is due to muscle imbalance. McBride concluded that angles up to $24^{\circ}$ are tolerable, whereas larger values require revision. Coughlin and Mann [1] reported hallux varus complication rates of $11 \%$, which led them to cease lateral sesamoidectomy. They stated that hallux varus is mainly due to muscle imbalance, which causes dislocation of the lateral sesamoid.

Medial cutaneous nerve injury or secondary nerve entrapment [19], hypoesthesia, and neuroma [31] have been reported as cutaneous neurological complications. In this study, various levels of hypoesthesia were present in the great toe and over medial incisions, as reported by patients during late postoperative physical examinations of eight feet $(22.2 \%)$.

Recurrence of hallux valgus of $72.2 \%$, which is quite high, was observed in this study, with $15^{\circ}$ accepted as the upper limit. The most common cause of recurrence in McBride procedure is insufficient attention to the metatarsus primus varus [1]. Treatment of a fixed bony deformity using a soft tissue procedure leads to insufficiency in many cases. Because of this, bony procedures should be added to the DSTP whenever needed, otherwise high recurrence may be inevitable as seen in our cases. In one study [7], recurrence was reported in 40 of 72 cases (56\%). The authors claimed this to be the result of weakness of medial joint structures, insufficiency of lateral release, pressure of the proximal phalanx on the metatarsal head, and rigidity of the 1.MTC. Dreeben and Mann [17] reported three recurrences in 39 cases. Patient compliance plays an important role in recurrence [16], and while the results of revision surgery, such as the modified McBride procedure with proximal crescentic osteotomy [16] or resection arthroplasty with arthrodesis [14], may be accepted as sufficient, they are not as good as those obtained following primary surgery.

Although osteotomies are more effective when using radiological criteria to measure the deformity, the McBride procedure is claimed to be more effective in alleviating pain [32]. This disharmony leads to the question of whether radiological evaluations are good criteria in a global evaluation of hallux valgus. We propose use of the McBride procedure in the treatment of mild hallux valgus, and osteotomy for severe deformities, keeping in mind that in this study the McBride procedure was found to be effective in alleviating pain.

Our study has a weakness that should be addressed in that quite a high number of patients were lost to follow-up: 14 out of 35 patients. This is thought to be related to the high ratio of internal migration.

The McBride procedure can be performed with satisfactory results by adhering to the algorithm prepared by Coughlin and Mann [1] and paying strict attention to the following criteria: the main complaint of the patient (pain/ cosmesis); his/her occupation (physically demanding/not), age (young/old), and athletic activities; physical findings (overriding, pronation, bunion deformity, ROM of the 1.MTP joint motor, and neurological examination); radiological evaluation [(HVA; $\left.<30^{\circ},<40^{\circ},>40^{\circ}\right),(1-2 . \mathrm{IMA}$; $\left.<13^{\circ},>13^{\circ},>20^{\circ}\right)$, (1.DMAA; $<10^{\circ},>10^{\circ}$ ), (interphalangeal angle, IPA; $\left.<10^{\circ},>10^{\circ}\right)$ ]; congruence of the 1.MTP joint (congruent/incongruent); presence of arthrosis in the 1.MTP; and the patient's expectations from surgery.

In this study, surgical decision-making was reevaluated by comparison with an algorithm designed to analyze treatment of hallux valgus deformities. Thirty-six feet of 21 
patients were evaluated by means of subjective evaluation and clinical and radiological findings. The hallux valgus angle preoperatively, early postoperatively, and late postoperatively was $32.7 \pm 8.5^{\circ}, 10.1 \pm 6.9^{\circ}$, and $20.6 \pm 9.5^{\circ}$, respectively. Recurrence of hallux valgus of $72.2 \%$ was observed. Subjective results were better and the patients rated their satisfaction with the procedure as excellent or high in 23 cases $(63.9 \%)$, and moderate, low, or unsatisfactory in 13 cases $(36.1 \%)$. This level of patient satisfaction demonstrates that the McBride procedure is an efficient approach for eliminating pain due to hallux valgus deformity.

\section{Conflict of interest None.}

Open Access This article is distributed under the terms of the Creative Commons Attribution Noncommercial License which permits any noncommercial use, distribution, and reproduction in any medium, provided the original author(s) and source are credited.

\section{References}

1. Coughlin MJ, Mann R (1999) Surgery of the foot and ankle. Mosby, St. Louis

2. Giannetras NJ (1973) Foot disorders. Lea \& Febiger, Philadelphia

3. Evarts CM (ed) (1983) Surgery of the musculoskeletal system. Churchill Livingstone, New York

4. McBride E (1928) A conservative operation for bunions. J Bone Joint Surg 10:735-739 (Reprinted, Clin Orthop 157:2-4, 1981)

5. McBride ED (1935) The conservative operation for bunions, end results and refinement of technic. J Am Med Assoc 105:11641168

6. McBride ED (1954) Hallux valgus, bunion deformity: its treatment in mild, moderate and severe stages. J Int Coll Surg 21:99105

7. Mann RA, Pfeffinger L (1991) Hallux valgus repair, DuVries modified McBride procedure. Clin Orthop 272:213-218

8. Pfeffinger LL (1990) The modified McBride procedure. Orthopedics 13:979-984

9. Meyer JM, Hoffmeyer P, Borst F (1987) The treatment of hallux valgus in runners using a modified McBride procedure. Int Orthop 11:197-200

10. Lin I, Bonar SK, Anderson RB, Davis H (1996) Distal soft tissue release using direct and indirect approaches: an anatomic study. Foot Ankle Int 17:458-463

11. Skinner HB (1995) Current diagnosis and treatment in orthopedics. Lange Medical, New York

12. Harris NJ, Scott B, Smith TWD (1997) A further modification to the McBride procedure for hallux valgus using the acufex tag system to reattach the adductor hallucis. Foot Ankle Int $18: 57-58$
13. Schneider W, Knahr K (1998) Metatarsophalangeal and intermetatarsal angle: different values and interpretation of postoperative results dependent on the technique of measurement. Foot Ankle Int 19:532-536

14. Kitaoka HB, Patzer GL (1998) Arhrodesis versus resection artroplasty for failed hallux valgus operations. Clin Orthop 347:208-214

15. Coughlin MJ, Carlson RE (1999) Treatment of hallux valgus with an increased distal metatarsal articular angle: evaluation of double and triple first ray osteotomies. Foot Ankle Int 20:762-770

16. Kitoaka HB, Patzer GL (1998) Salvage treatment of failed hallux valgus operations with proximal first metatarsal osteotomy and distal soft tissue reconstruction. Foot Ankle Int 19:127-131

17. Dreeben S, Mann RA (1996) Advanced hallux valgus deformity: long-term results utilizing the distal soft tissue procedure and proximal metatarsal osteotomy. Foot Ankle Int 17:142-144

18. Geary NPJ, Mittal D (2000) A prospective study of modified McBride procedure for hallux valgus-short term results. J Bone Joint Surg 82-B:203-207

19. Johnson JE, Clanton TO, Baxter DE, Gottlieb MS (1991) Comparison of Chevron osteotomy and modified McBride bunionectomy for correction of mild to moderate hallux valgus deformity. Foot Ankle Int 12:61-68

20. Gebuhr P, Soelberg M, Larsen TK, Niclasen BV, Laursen NO (1992) McBride operation for hallux valgus. Acta Orthop Scand 63:189-191

21. Archibald DAA, Hamilton JA (1990) Modified McBride procedure: long-term results. J R Coll Surg Edinb 35:317-319

22. Judge MS, Lapointe S, Yu GV, Shook JE, Taylor RP (1999) The effect of hallux abducto valgus surgery on the sesamoid apparatus position. J Am Podiatr Med Assoc 89:551-559

23. Mann R, Rudicel S, Graves SC (1992) Repair of hallux valgus with a distal soft-tissue procedure and proximal metatarsal osteotomy. J Bone Joint Surg 74-A:124-129

24. Talbot KD, Saltzman CL (1998) Assessing sesamoid subluxation: how good is the AP radiograph? Foot Ankle Int 19:547-554

25. Weissman SD (1989) Radiology of the Foot. Williams \& Wilkins, Baltimore

26. Weinfeld SB, Schon LC (1998) Hallux metatarsophalangeal artritis. Clin Orthop 349:9-19

27. Okuda R, Kinoshita M, Morikawa J, Jotoku T, Abe M (2000) Distal soft tissue procedure and proximal metatarsal osteotomy in hallux valgus. Clin Orthop 379:209-217

28. Tetik C, Özkan İ, Tuğrul Ş (1991) Modifiye McBride operasyon sonuçları. Acta Orthop Traum Turc 25:1-3

29. Schwitalle M, Karbowski A, Eckardt A (1997) Hallux valgus in young patients:long-term results after McBride operation. Acta Orthop Trauma Surg 116:412-414

30. Trnka HJ, Zettl R, Hungerford M, Mühlbauer M, Ritschl P (1997) Acquired hallux varus and clinical tolerability. Foot Ankle Int 18:593-597

31. Solan MC, Lemon M, Bendall SP (2001) The surgical anatomy of the dorsomedial cutaneous nerve of the hallux. J Bone Joint Surg 83-B:250-253

32. Udin B, Dutoit M (1992) Hallux valgus: intervention de McBride ou osteotomie sous-capitale. Rev Chir Orthop Reparatrice Appar Mot 78:169-175 